\title{
Governmental Support of Innovative and Industrial Development of the Economy
}

Turysbekova Gulzhan

Euroasian National University named after L.N.Gumilev, 010008, Republic of Kazakhstan, Astana city, K. Munaitpasov street 5, 615 office (Department of Tourism)

Ospanov Yerzhan

Euroasian National University named after L.N.Gumilev, 010008, Republic of Kazakhstan, Astana city, K. Munaitpasov street 5, 803 office (Department of Economic)

\author{
Alimkulova Elvira \\ International Kazakh-Turkish University named after A. Yasawi, 161200, Republic of Kazakhstan, \\ Turkestan city, Rectorate, Department of Economic
}

\section{Doi:10.5901/mjss.2015.v6n3p445}

\section{Abstract}

The article studies peculiarities of implementation of governmental support of industrial and innovative development of the economy; theoretical aspects of the incentive function of the state and main forms and methods of supporting the innovation sphere. It provides analysis of the experience of Kazakhstan, identifies typical attributes of governmental support of industrial and innovation activities, formulates main problems of participation of the state in innovative projects, and development of the algorithm of assessment of governmental support of innovative small business.

Keywords: innovations, state, development, Kazakhstan, support, small businesses, assessment.

\section{Problem Definition}

Presently, the social progress is based on development of the industrial and innovation activities. Taking this into account, many countries treat implementation of industrial and innovation development as one of strategic directions of state regulation of the economy. The industrial and innovation development targets stable development of the country through mastering production of conceptually new types of products and technologies, expansion of native goods' markets based on it. It is to be noted that the process of reframing the necessity to move to the new type of economic systems' development in different institutions of different countries is carried out without coordination either of time or of the concept. And in such countries as Russia, Ukraine, Kazakhstan and other CIS countries, this process is at the initial stage currently, which is clearly evidenced by Figure 1.

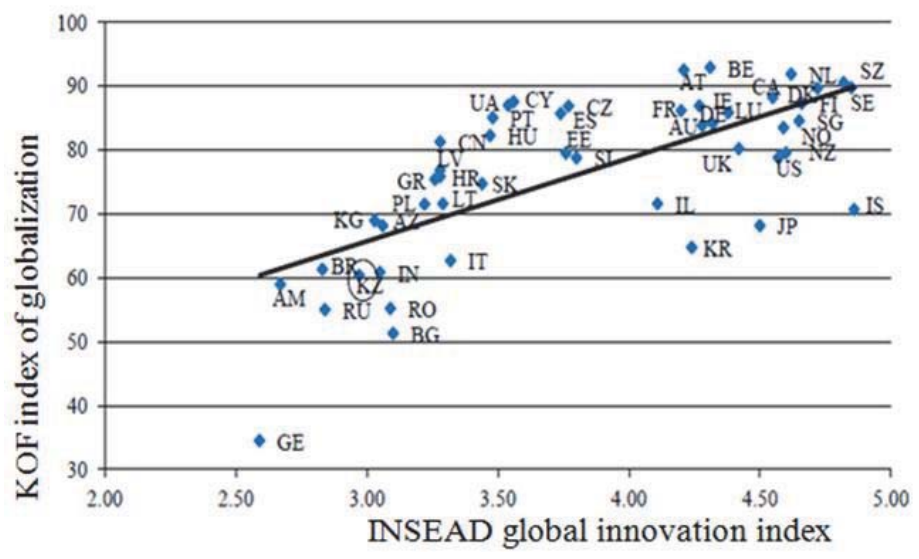

Figure 1. Globalization and innovations [INSEAD, Switzerland School of Economics, www.worldbank.org/reference, 2013] 
Kazakhstan is especially interesting in this context, as it gradually develops innovative economy and, for example, moved up by 8 points for the period 1995-2009 by the knowledge economic index (KEI), and up from 84 $4^{\text {th }}$ position in 2011 to $83^{\text {rd }}$ position in 2012 with regard to the global innovation index. This progress was facilitated by the fact that industrial and innovation development is one of priorities of the national strategy and policy of Kazakhstan. All main elements of the modern innovation system have already been formed and function in the country. However, prospects of further development and its acceleration depend greatly on how efficiently governmental support of industrial and innovation development of the economy will be provided; and whether mechanisms of focusing state and business resources on development of prioritized innovative sectors of the economy will be efficient, and whether usage of advanced information systems of monitoring specific instruments of industrial and innovation policy implementation will manage to give effective output.

Thus, these circumstances confirm the vitality of the research subject and form its composition platform, goals and objectives.

\section{Analysis of Latest Researches and Publications}

Many fundamental researches are dedicated to issues of state regulation of industrial and innovation development of the economy (Volkova \& Sakhno, 2005; Geets, 2007; Zyanko, 2008; Kolokolov, 2012; Mendaliyeva, 2010; Yulenkova, 2012) and other authors can be included in this list.

\section{Unresolved Parts of the Problem}

Despite significant number of works, most of them are dedicated to peculiarities of governmental support in developed countries. It is obvious that clearly formulated recommendations are not always acceptable for countries with transitive economy. Besides, issues, related to mechanisms and instruments of governmental support have yet been studied tenuously as governments of developing countries pay for actions of specialists rather than for intellectual property. The problem of governmental support of innovations, which face absence of market demand, also requires to be analyzed further. As for Kazakhstan, the debating points are the issues of economic and organizational grounds of state encouragement of industrial and innovation activities in economy sectors of high priority.

The research objective is to study theoretical and key aspects of governmental support of industrial and innovation development of the economy, consideration of peculiarities and problems of the implementation of state incentives of innovation sphere in Kazakhstan.

\section{General Results of the Research}

The main objective of the governmental support of the industrial and innovation development of the economy is creation of social and economic, organizational and regulatory positions for efficient formation, development and application of scientific and technical potential of the country as well as implementation of advanced technologies of production and sale of new types of competitive products. Government intervention in the behavior of innovative processes is necessary for creating incentives for innovations that are not created by the market institutional environment.

In the world, there are two efficient models of government support of industrial and innovation development: the American and the Japan models. The American model assumes maximum autonomy of entrepreneurial activity, which is engaged in developing innovations. This model is based on the principles of free competition and orientation to technological development. Implementation of the supporting functions of the state is carried out by way of defining a sector of the highest priority. The Japan model assumes that the government ensures technological prerogatives through encouraging specific technologies, rather than single sectors (Grechko, 2012). At that, the government support can be rendered directly by granting money from the budget or by distribution of money through special non-budgetary funds or in the form of indirect influence, which assumes granting tax releases, privileges to subjects of innovative sphere. The authors believe that for developing countries, such direction of development must become dominant, which is based on application of the strategy of industrial and innovation potential building in prioritized directions of progress in science and technology as the government determines. In this context, developing innovative programs and establishing a legal base for the innovative activity seems to be most important.

The main instruments and mechanisms of encouraging and supporting the industrial and innovation development of the economy include:

- subsidizing companies in a competitive order by prioritized directions of their innovative activities: 
- creating conditions for efficient operation of innovative financial and credit institutions and investment businesses;

- encouraging directly state sector companies as well as companies that operate in the natural monopoly sphere to form and implement industrial and innovation development programs;

- $\quad$ supporting science development at economic entities;

- using instruments of tax incentives of innovative activities of companies;

- ensuring formation and development of the direct investment and venture capital industry for attracting investments in international capital markets;

- developing innovation infrastructure;

- improving efficiency and transparency of mechanisms of the public and private partnership;

- improving the export system with regard to high technology goods and services and the import system with regard to standalone foreign technologies, which are very prospective for distribution in the economy;

- forming internal relations at state-owned companies, which would encourage creating various organizational forms of market-type economic activity and attraction of private investments including investments in the innovation sector.

The authors believe that particular attention in the process of formation of the mechanism of governmental support of industrial and innovation development of the economy must be paid to revealing interrelations between the forms and the methods as well as the expected results of such rendering governmental support to innovation companies and sectors, functions and instruments of such support.

1. As it has been noticed before, the industrial and innovation development of Kazakhstan, which is based on implementation of new ideas, scientific knowledge, technologies and types of products in various spheres of production and society management, is one of the most important factors of the Republic's economy development. General provisions of the Law of the Republic of Kazakhstan On governmental support of industrial and innovation activities (www.kz.government.kz/docs/z120000053420120109 2, 2013) and the Program of innovative development of the Republic of Kazakhstan target the expansion of the scopes of industrial and innovation activities in Kazakhstan. In 2010, the Strategic plan of development of the Republic of Kazakhstan until 2020 was approved. Its main objective is ensuring qualitative growth of the economy through its modernization, development of human resources and improvement of the institutional base, which, in their turn, are to facilitate the accelerated industrial and innovation development of the country and the increase of the citizens' prosperity level (Grechko, 2012). The government program of accelerated industrial and innovation development of the Republic in 2010-2014 prescribes formation of favorable environment for investors who are ready to implement projects in the following prioritized sectors of the economy:

- oil refining and infrastructure of the oil and gas sector, the mining and smelting industry, nuclear and chemical industry with further upgrade of rough manufacturing to higher levels;

- mechanical engineering, building industry, pharmaceuticals industry;

- agricultural, consumer and travel industries;

2. information and communication technologies, biotechnology, alternative energetics, space industry (On Governmental Support of Industrial and Innovation Activities, www.kz.government.kz/docs/z120000053420 120109 2, 2013).

The planned total value of the program is 60 billion tenges (approximately 400 million US Dollars), of which 36 billion tenges (approximately 240 million US Dollars) will be financed by the budget directly. Main objectives of the program are provided in Table 1.

Table 1. Main objectives of the Program of innovation development and facilitation of technological modernization in 2010-2014 (INSEAD, Switzerland School of Economics, www.worldbank.org/reference, 2013)

\begin{tabular}{|l|c|c|c|c|}
\hline Targeted values & $\mathbf{2 0 1 1}$ & $\mathbf{2 0 1 2}$ & $\mathbf{2 0 1 3}$ & $\mathbf{2 0 1 4}$ \\
\hline Innovative activities of companies in 2015, (\%) & 4.8 & 6.8 & 8.8 & 10 \\
\hline Government expenses for science and innovations in percentage of the GDP & 0.4 & 0.6 & 0.8 & 1 \\
\hline The share of innovative products in the aggregate value of the GDP, (\%) & 0.6 & 0.7 & 0.85 & 1 \\
\hline Expenses for technology innovations in industry, million tenges. & 45,000 & 60,000 & 75,000 & 98,000 \\
\hline
\end{tabular}

The program is supposed to facilitate the increase of demand for innovations through tax releases, state purchasing and 
technological agreements with national and foreign companies.

Analysis of the legislative grounds of the innovation sphere functioning in Kazakhstan allows to admit that legislative base for the formation, development and support of industrial and innovation development of the country has been created. And the work on improvement of the legislative base is permanently carried out. An indicative fact is that issues of the governmental support of the industrial and innovation development are managed by three main public regulatory authorities, namely: the Ministry of Economy and Trade, the Ministry of Education and Science, and the Ministry of Energy and Mineral Resources, and the majority of innovatively proactive businesses are owned by the government, which is evidenced by the statistics given in Figure 2 .

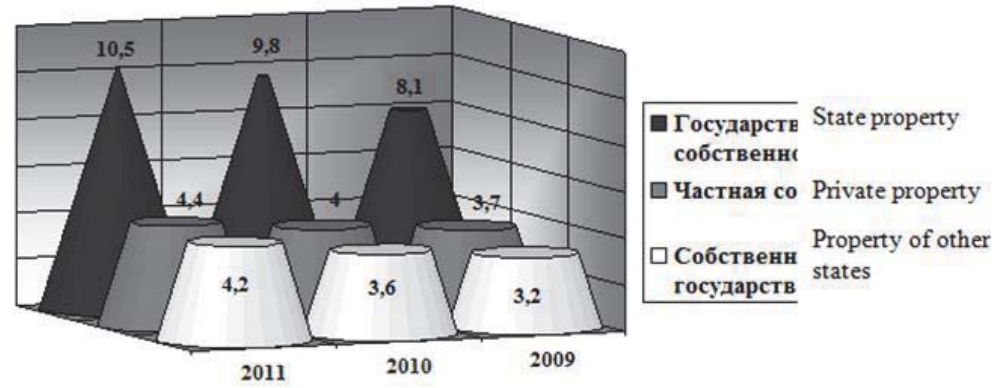

Figure 2. Innovative activeness of Kazakh companies in proportion to their forms of incorporation (\%) (Strategic Plan of Development of the Republic of Kazakhstan until 2020, www.akorda.kz/kz/category/gos_programmi_razvitiya, 2013)

Despite the drastic growth rate and rapid development of the innovation sphere in Kazakhstan, it is to be noted that the progress of these processes is accompanied with certain difficulties, obstacles and contradictions. Improper operation of the governmental infrastructure of innovation support can be also considered as a problem of the governmental support of the industrial and innovation development of the economy of Kazakhstan. Main difficulties in this issue relate to the efficiency of the performance of these bodies, and they require a comprehensive approach to their solution. Every element of the innovation support infrastructure functions separately from the others and the incentive measures often do not facilitate rapid growth of innovative businesses.

Such certain difficulties relate to the support of small and medium entrepreneurship, which is the impelling force of the formation and development of the innovation market. It is also worth noting that entrepreneurship in Kazakhstan is mostly non-productive, and does not have the target to create and implement innovations. Its goal is only to earn profit by re-distribution of existing wealth. To balance these weak chains, it is necessary to elaborate a new state policy of supporting the small entrepreneurship based on innovations, which would target first of all development of its innovative side based on competition principles. The objective of the state policy of supporting the small entrepreneurship in the innovation sphere is multi-criteria optimization, which allows to form a comprehensive assessment of its strategic directions of development. The comprehensive assessment in aggregate must consider all objectives of the program.

Let us consider a detailed algorithm of assessing governmental support of the innovative small entrepreneurship.

$K_{t}=\left(K_{t}, \cdots \cdot K_{t,}, \cdots \cdot K_{n t}\right)$

$A_{t}=\left(A_{1 t}, \cdots \cdot A_{i t}, \cdots \cdot A_{n t}\right)$

where $K_{t}$ and $A_{t}$ are the vectors, which describe the state of the system (aggregate number of studied small businesses) at the $t$ moment;

$K_{i t}$ - basic capital of the $i$ company at the $t$ moment;

$A_{i t}$ - productivity of capital for the $i$ company at the $t$ moment;

$n$-total number of studied small businesses involved in innovation processes;

$t$ - time reference.

Now let us specify the list of directions of governmental support of small businesses:

- normalization of statutory regulation of entrepreneurship (A);

- financial and credit support; investment support (X);

- resources and information provision, infrastructure formation (Y);

Based on that the object of the research is the governmental support of innovative small businesses, it seems reasonable to include two more directions in the list: 
- $\quad$ formation of the virtual market $(F)$;

- development of environmental entrepreneurship (Z);

Let us assume that the assessment of selected directions will be carried out through $m$ number of criteria. Let us specify $x_{j}$ as a value of $j^{\text {th }}$ criterion of the direction. Then, the following convolution will be the form of representation of comprehensive assessment:

$$
F=\sum_{j=1}^{m} \lambda_{j} x_{j}
$$

where $\lambda_{j}$ is the weight of the $j^{\text {th }}$ criterion, which is mainly determined as a consequence of the expert assessment;

According to the methodology of multi-criteria comprehensive optimization, where every variant differs at least by one criterion, it is necessary to select the efficient (Pareto optimal) variant, i.e. such variant, which is the only best one by all criteria.

Let us set $m=2$ in the convolution formula, and we will sequentially receive the following formula of assessment of each direction:

$$
F=\lambda_{1} x_{1}+\lambda_{2} x_{2}
$$

where $x_{1}$ is the value of efficiency of a certain direction by criterion 1 ;

$x_{2}$ are the values of efficiency of a certain direction by criterion 2 .

The resulting values of the governmental support efficiency should be reasonably divided into 4 groups:

- values of expenses (scopes and structure of the resources, which ensure implementation of the budget program);

- product values (scope of manufactured products or rendered services by small businesses during implementation of the budget program, number of consumers of goods (works, services), etc.);

- values of efficiency (resources spent for a product unit, i.e. economy; the ratio of maximum number of manufactured products (completed works, rendered services) to the scope of invested financial resources, i.e. productivity; achievement of certain results, i.e. effectiveness);

- values of quality (the aggregate properties characterizing the achieved quality results of the created product, which satisfy consumers in accordance with their purpose and which mirror the weakening of negative or strengthening of positive trends in rendering services to consumers at the expense of the budget program).

Let us formalize some of the described criteria. system:

Taking into account governmental support, productivity of small innovative businesses is determined by the

$$
A_{i t}^{n}=\left\{\begin{array}{c}
\left(A_{i t}+\Delta A_{i t}\right), \theta_{i t}^{n}=1 \\
A_{i t}, \boldsymbol{\theta}_{i t}^{n}=0
\end{array}\right.
$$

where $\theta$ nit is the Boolean variable equal to zero (if investments in innovations do not cause changes of the capital productivity), or equal to one (if investing in innovations results in changes of the capital productivity).

At the heart of such dependency, the critical (marginal) level of state investment is (Rkp):

$$
\begin{aligned}
& R_{i t}^{n}<R_{k p} \Rightarrow \theta=0 \\
& R_{i t}^{n}<R_{k p} \Rightarrow \theta=1
\end{aligned}
$$

Calculation of changes of small businesses' capital is made in the following way:

- profitability $\pi_{i t:}$

$\pi_{i t}=\frac{Z_{i t}}{K_{i t}}$

- financial limits of granted state resources / $/$ max $_{i t:}$ :

$I_{i t}^{\max }=G\left(\pi_{i t}, b\right) \bullet k_{i t}=Z_{i t}(1-b)$;

where $G$ is the function, which determines the maximum of gross investments per a capital unit;

$b$ is the share of external financing in the economic profit.

- calculation of expected investments in technology innovations. The expected investments depend on the market share $\left(\mu_{i t}\right)$, ratio of capital to output $\left(k_{i t}\right)$ and fixed capital depreciation ratio $(\delta)$ of small businesses:

$I_{i t}^{\text {des }}=H\left(k_{i t}, \mu_{i t}, \delta\right) \cdot K_{i t}$

Expected investments of small businesses depend on the ratio of price of products in the current period to the cost unit of the next period $(t+1)$, taking into account the change of productivity; objective inflator, which is an increasing 
function of the market share of small innovative businesses.

As the resulting values of operation efficiency and quality of small innovative businesses mirror the end results of the state program implementation, it is reasonable to provide assessment of governmental support by complex criteria, which would enable us to take into account various efficiency directions (economical, social, environmental, etc.) The author believes that in this case the qualitative parameters must be determined by expertise through a scoring scale of attributes of indicators and values of weight numbers (weights) of importance of these indicators.

An important indicator for determining the efficiency of invested government funds in innovative small businesses is the elasticity of new innovative product manufacturing with respect to the scope of innovation costs as well as to the number of active innovative businesses. This indicator points at the relative change of the resulting value by just $1 \%$ change of the factor. The elasticity ratio is calculated in the following way:

$$
\widehat{E}_{k}=\widehat{\beta}_{k} \cdot \frac{\overline{x_{k}}}{y}
$$

where $\widehat{\beta}_{k}$ is a standardized parameter;

$\overline{x_{k}}, y$ is the value of regressors and the regressand for such point of the regression function, for which the elasticity ratio is calculated.

Upon finishing all calculations, the new state of small businesses, which use governmental support at the $t+1$ moment, is formed.

The algorithm proposed by the author and the set of above mentioned models is evaluated with materials of innovative small businesses of Russia, which are engaged in development of innovations in healthcare.

For the chosen five basic options of directions $A, X, Y, F$, and Z, the following assessments of values were determined through an expert survey (the assessment was carried out by two comprehensive criteria -economic feasibility and efficiency) (refer to Table 1 ) and their comparative efficiency was described with the following inequality: $X>A>Y>F>Z$

Table 1. Expert assessment of options of governmental support of innovative small businesses in healthcare by comprehensive criteria.

\begin{tabular}{|c|c|c|c|c|c|}
\hline \multirow{2}{*}{ Criteria } & \multicolumn{5}{|c|}{ Directions } \\
\cline { 2 - 6 } & $\mathrm{A}$ & $\mathrm{X}$ & $\mathrm{Y}$ & $\mathrm{F}$ & $\mathrm{Z}$ \\
\hline Economic feasibility & 3 & 6 & 5 & 2 & 1 \\
\hline Efficiency & 5 & 1 & 4 & 7 & 8 \\
\hline
\end{tabular}

It is obvious that the weights $\lambda_{1}$ and $\lambda_{2}$ must have such values, which would make the following inequalities true:

$5 \cdot \lambda_{1}+\lambda_{2}>3 \cdot \lambda_{1}+6 \cdot \lambda_{2}>4 \cdot \lambda_{1}+4 \cdot \lambda_{2}>2 \cdot \lambda_{1}+8 \cdot \lambda_{2}>\lambda_{1}+9 \cdot \lambda_{2}$

Let us solve the tasks of linear programming: let us define $\lambda 1, \lambda 2$ and $\varepsilon$, which are equal to:

$\varepsilon \rightarrow \max ;$

$\lambda_{1}+\lambda_{2}=1$

$5 \cdot \lambda_{1}+\lambda_{2} \leq 3 \cdot \lambda_{1}+6 \cdot \lambda_{2}+\varepsilon$

$3 \cdot \lambda_{1}+6 \cdot \lambda_{2} \leq 4 \cdot \lambda_{1}+4 \cdot \lambda_{2}+\varepsilon$

$4 \cdot \lambda_{1}+4 \cdot \lambda_{2} \leq 2 \cdot \lambda_{1}+8 \cdot \lambda_{2}+\varepsilon$

$2 \cdot \lambda_{1}+8 \cdot \lambda_{2} \leq \lambda_{1}+9 \cdot \lambda_{2}+\varepsilon$.

As a result, we receive the following values: $\varepsilon=-0.1, \lambda_{1}=0.7, \lambda_{2}=0.3$

According to the received values of the weights, the comprehensive assessments of governmental support option are as follows: $F_{A}=3.9 ; F_{B}=3.8 ; F_{C}=4 ; F_{D}=3.5 ; F_{E}=3.4$. From the represented assessments, it is obvious that the best option of governmental support of innovative entrepreneurship in medical care and technology is the $Y$ option - the resources and information provision, and the formation of infrastructure (refer to Table 2).

$$
\mathrm{Y} \leq \mathrm{A}, \mathrm{Y} \leq \mathrm{X}, \mathrm{Y} \leq \mathrm{F}, \mathrm{Y} \leq \mathrm{Z}
$$

Table 2. Results of selecting the efficient prioritized direction of governmental support of innovative small businesses

\begin{tabular}{|c|c|c|c|c|c|}
\hline \multirow{2}{*}{ Criteria } & \multicolumn{5}{|c|}{ Directions } \\
\cline { 2 - 6 } & $\mathrm{A}$ & $\mathrm{X}$ & $\mathrm{Y}$ & $\mathrm{F}$ & $\mathrm{Z}$ \\
\hline Economic feasibility & 3 & 6 & 5 & 2 & 1 \\
\hline Efficiency & 5 & 1 & 4 & 7 & 8 \\
\hline
\end{tabular}


We need to draw your attention to the fact that direction of development of environmental entrepreneurship has the highest level according to expert assessments. However, taking into account the low value of the comprehensive efficiency assessment, it is reasonable to introduce a certain program on formation of resource and information coverage for implementation of environmental entrepreneurship in the $Y$ direction, which is the resource and information provision.

Calculations given below allow to represent the extent and the changes of innovative development (productivity and profitability) of small healthcare businesses, i.e. their evolution after governmental support has been rendered to them, forecast prospects and maintaining their market share due to it.

Table 3. Development of innovative healthcare businesses participating in governmental support programs

\begin{tabular}{|c|c|c|c|c|c|c|c|c|c|c|}
\hline \multicolumn{3}{|c|}{2010} & \multicolumn{3}{|c|}{2012} & \multicolumn{3}{|c|}{2014} & \multirow[t]{2}{*}{ constant } & \multirow[b]{2}{*}{ 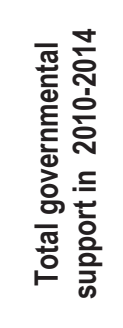 } \\
\hline 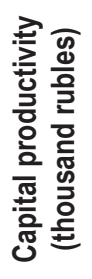 & 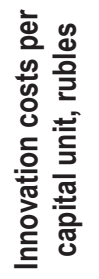 & 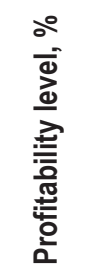 & 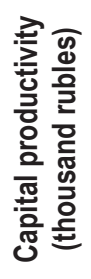 & 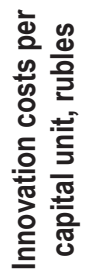 & 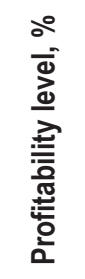 & 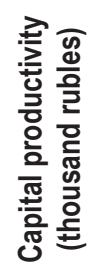 & 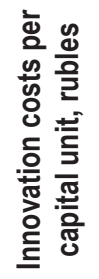 & 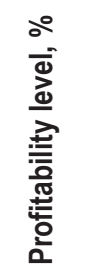 & & \\
\hline 4.536 & 0.736 & 42.9 & & 0.832 & 43.8 & 5.432 & 0.965 & 45.9 & 0.030 & 44935.52 \\
\hline 1.832 & 0.096 & -24.7 & 2.16 & 0.54 & $-20,3$ & 2.56 & 0.67 & -15.4 & 0.018 & 38949.31 \\
\hline 4.643 & 1.544 & 10.8 & 4.36 & 0.716 & 27.7 & 4.76 & 0.812 & 31.6 & 0.049 & 72437.87 \\
\hline 4.392 & 2.04 & 41.7 & 3.972 & 0.82 & 43.7 & 4.123 & 1.024 & 51.7 & 0.060 & 113354.3 \\
\hline 4.792 & 1.052 & 46.6 & 4.948 & 0.716 & 50.5 & 5.134 & 0.814 & 52.4 & 0.074 & 96148.15 \\
\hline 3.932 & 1.916 & 1.9 & 3.344 & 0.572 & 24.9 & 3.678 & 0.532 & 25.8 & 0.040 & 58618.04 \\
\hline 4.084 & 1.472 & 16.1 & 3.78 & 0.608 & 22.6 & 4.76 & 0.864 & 24.6 & 0.040 & 55771.32 \\
\hline
\end{tabular}

As evidenced by the Table 3 data, participation in programs of governmental support incurs increase of capital profitability and productivity. The strategy of further support of analyzed businesses must continue in the same investment direction, i.e. investment of money in their business is reasonable, incurs increase of efficiency both of such companies' performance and performance of the whole sector they render their services to. There is no doubt that there are such representatives in the market, supporting which is inefficient, and the only result will be outflow of state funds without due return. As a result, such strategy becomes a strategy of disinvestment, i.e. unreasonable investment of resources, and the businesses, which receive the support, should leave the market.

\section{Summary}

Thus, summarizing the fulfilled research, we can emphasize the following:

Building an innovative society is possible only with proactive governmental support, offering long-term incentives of industrial and innovation development, and encouraging fundamental and corporate sciences. A vital objective of innovation market development is the improvement of the mechanism of selecting innovative projects by the government with further support of their commercialization and introduction in the market as an innovation. As practice evidences, efficient functioning of the innovation sphere self-regulation is not possible for developing countries. In this case, it is necessary to implement relevant adequate programs of governmental support of industrial and innovation development of the economy. And Kazakhstan is a successful example of elaboration and application of such programs. The government of this country directs considerable resources for supporting innovative activity, implements various forms and methods of encouraging industrial and innovation spheres of activity. Along with existing practices and achievements, Kazakhstan faces certain problems, which require reorganization of mechanisms and instruments of the governmental support of the industrial and innovation development of the economy. This article offers an efficiency assessment algorithm for the governmental support with respect to innovative small businesses. However, despite its efficiency, it is to be noted that each specific governmental program is unique, and, therefore, efficient strategic solutions on rendering support to certain innovative spheres must be based on a synthesis of results of modelling and comprehensive analysis of the economic, social and environmental components of such program implementation. 
It is reasonable to focus further research on considering the most efficient ways and methods of supporting Kazakhstan innovative clusters' development through such measures as: development of a system of their financial and credit support, establishment of an efficient innovative infrastructure, implementation of an efficient technology transfer mechanism.

\section{References}

INSEAD Research: Global Innovation Index. Retrieved 2012, from www.gtmarket.ru/news/2012/07/06/4531

INSEAD, Switzerland School of Economics. Retrieved 2013, from www.worldbank.org/reference

Iskendirova, S., and Kabdusheva A. (2013) Investment Activities in Kazakhstan: Current Aspect, International Economic Forum, from www.be5.biz/ekonomika1/r2012/3647

Gaets, V.M. (2007). Strategic Challenges of the XXI Century to the Society and the Economy of Ukraine. Innovative and Technologic Development of the Economy, 2, 564

Global Innovation Index. Retrieved 2011, from www.agequal.ru/Archive_news/0207

Grechko, M.V. (2012). Innovative Development of Economy Based on Human Capital Management. Rostov-on-Don: Pedagogic Institute of the Southern Federal University

Kolokolov, V.A. (2012). Innovative Development of the Economy. Moscow: Plekhanov Russian University of Economics.

Mendalieva, S.I. (2010). Financial and Investment Provision of Innovations in the Development of the Economy of Kazakhstan. Volga Region State University of Service Newsletter: Economic Series, 11, 8-12

On Governmental Support of Industrial and Innovation Activities. Retrieved 2013, from www.kz.government.kz/docs/ z120000 053420120109 2

Review of Innovative Development of Kazakhstan. (2012). New York, Geneva: UNO, from www.unece.org/fileadmin/DAM/ ceci/publications/icp5_r.pdf

State Program of Accelerated Industrial and Innovation Development of the Republic of Kazakhstan in 2010-2014 and on Declaring Certain Decrees of the President of the Republic of Kazakhstan to Be No Longer in Force. Retrieved 2009, from www.adilet.zan.kz/kaz/docs/U100000958

Strategic Plan of Development of the Republic of Kazakhstan until 2020. Retrieved 2013, from www.akorda.kz/kz/category/ gos_programmi_razvitiya

Volkova, N., and Sakhno, T. (2005). Industrial Clusters. Saint Petersburg: ASMI Publishing House

Yulenkova, I.B. (2012). Theoretical Aspects of the Formation and Development of Innovation Infrastructure of Governmental Support of Small Businesses. ENGECON Newsletter: Economic Series, 2, 47-50

Zyanko, V.V. (2008). Innovative Entrepreneurship: Essence, Mechanism and Forms of Development. Vinnitsa: USVERSUM 